\title{
Unscented Kalman Filter and Control in TSE(3) with Applications to Spacecraft Dynamics
}

\author{
Gennaro Mangiacapra \\ Politecnico di Torino \\ Morad Nazari \\ Embry-Riddle Aeronautical University \\ Elisa Capello \\ Politecnico di Torino
}

Matthew Michael Wittal ( $\square$ matthew.m.wittal@nasa.gov)

NASA John F Kennedy Space Center https://orcid.org/0000-0002-2127-2318

\section{Research Article}

Keywords: special Euclidean group SE, tangent bundle TSE, Morse-Lyapunov

Posted Date: May 17th, 2021

DOI: https://doi.org/10.21203/rs.3.rs-522348/v1

License: @ (i) This work is licensed under a Creative Commons Attribution 4.0 International License. Read Full License 


\section{Abstract}

This paper presents a novel rigid-body spacecraft navigation and control architecture within the framework of special Euclidean group SE(3) and its tangent bundle TSE(3) while considering stochastic processes in the system. The proposed framework combines the orbit-attitude motions of the spacecraft into a single, compact set. The stochastic state filter is designed based on the unscented Kalman filter which uses a special retraction function to encode the sigma points onto the manifold. The navigation system is then integrated to an almost globally asymptotically stabilizing Morse-Lyapunov-based control system with backstepping. Numerical simulations are conducted to demonstrate the effectiveness of the proposed navigation filter for the full state estimation. In addition, the navigation and control system is tested in the nonlinear gravity field of a small celestial body with an irregular shape. In particular, the performance of the closed-loop system is studied in a tracking problem of spacecraft motion near the asteroid Bennu based on the OSIRIS-REx's mission data.

\section{Full Text}

Due to technical limitations, full-text HTML conversion of this manuscript could not be completed. However, the manuscript can be downloaded and accessed as a PDF.

\section{Figures}




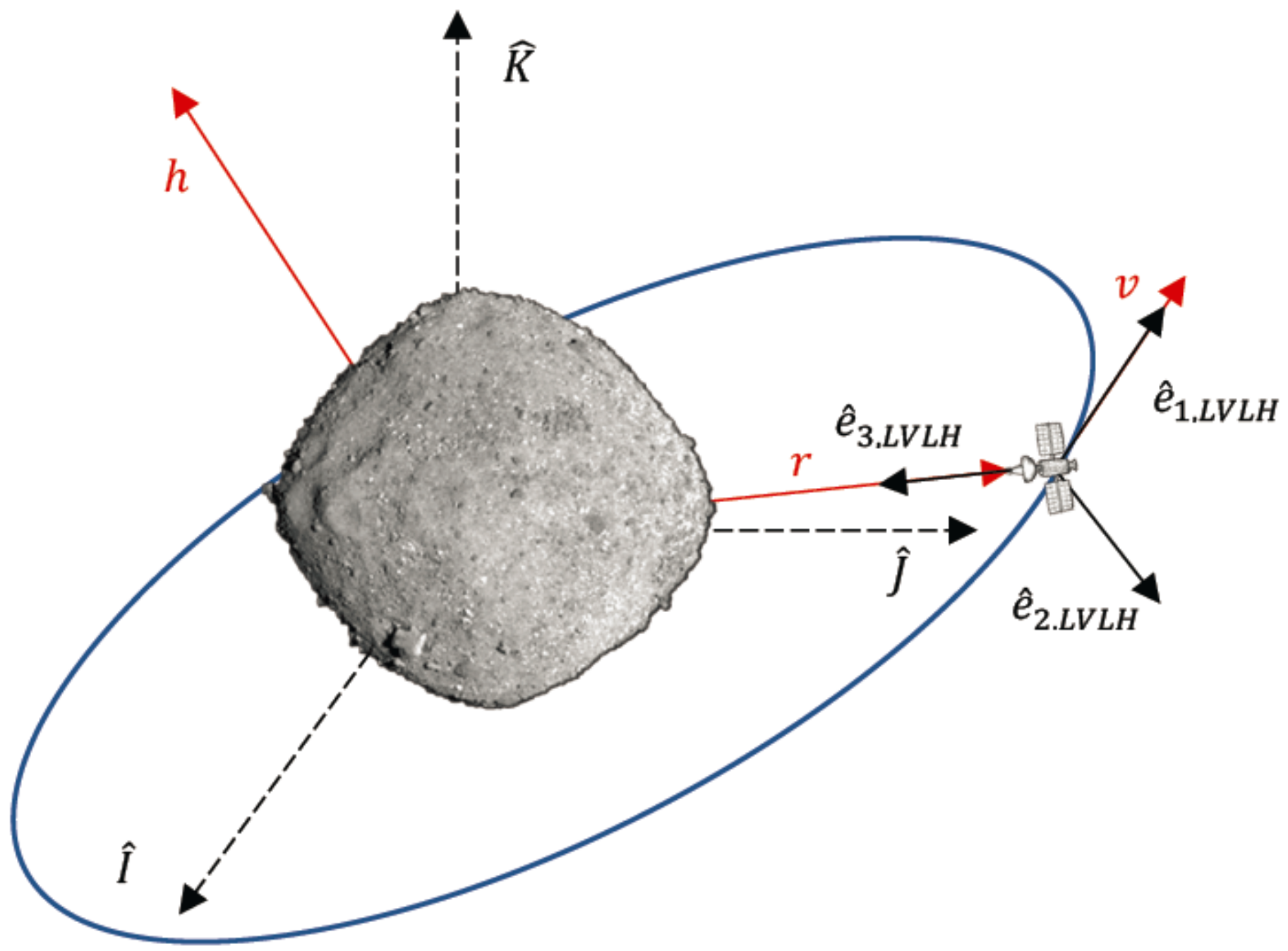

Figure 1

Local vertical local horizontal (LVLH) and bodycentered inertial (BCl) reference frames representation. 

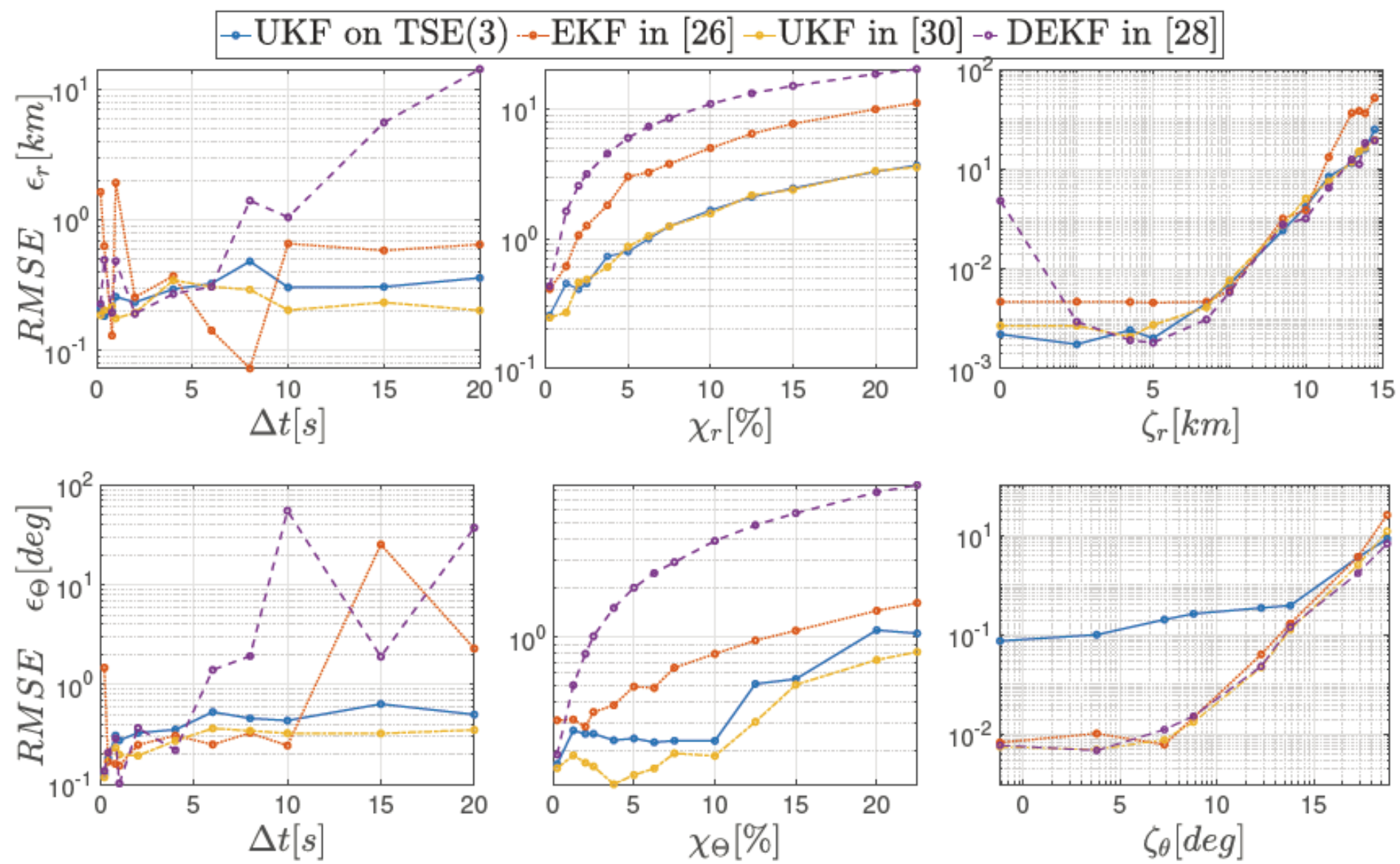

Figure 2

Attitude and position RMSE as a function of sample period, initial condition inaccuracies and measurement noise standard deviations. 

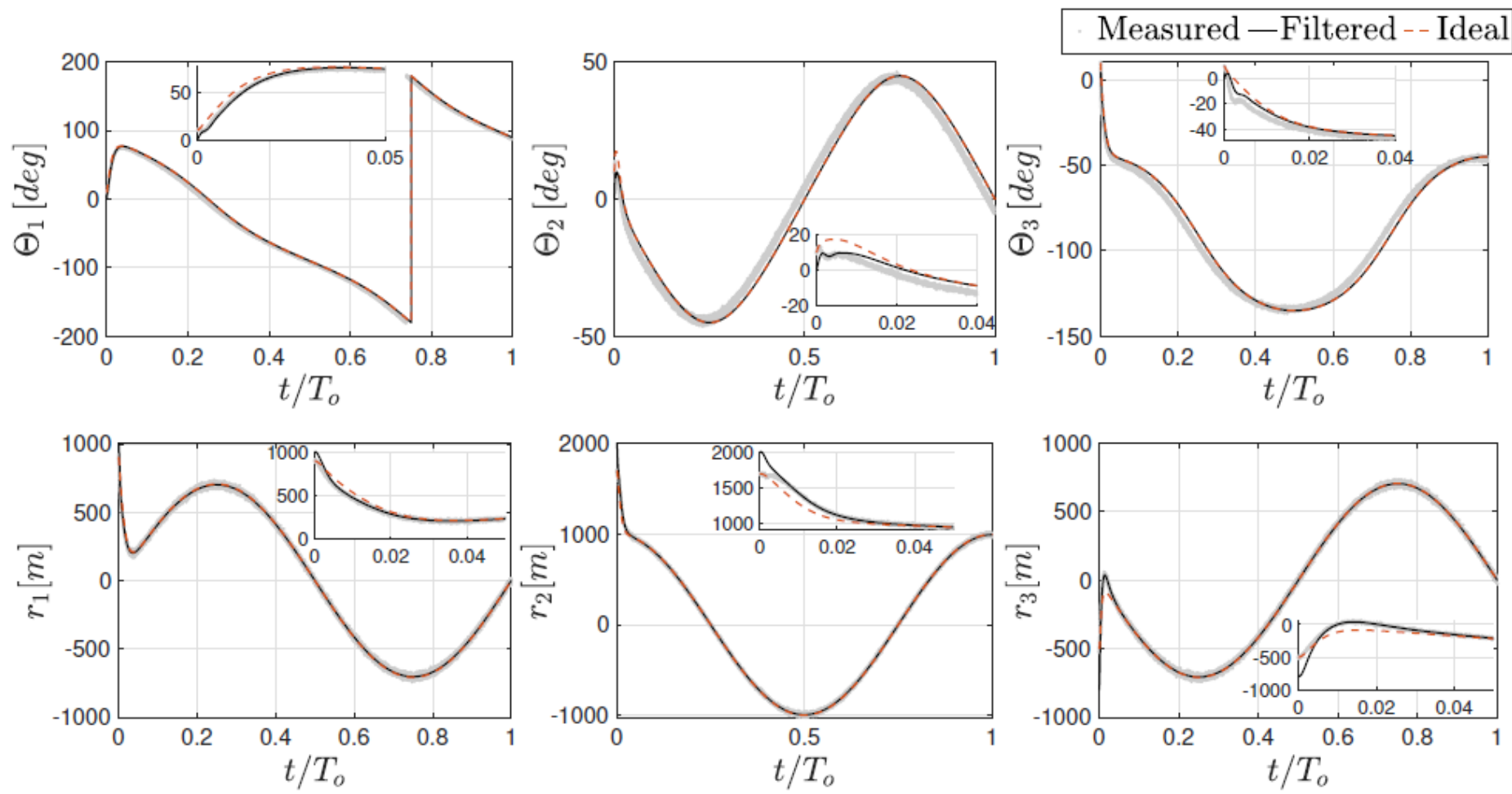

Figure 3

Measured (grey), estimated (black), and ideal (red) states.
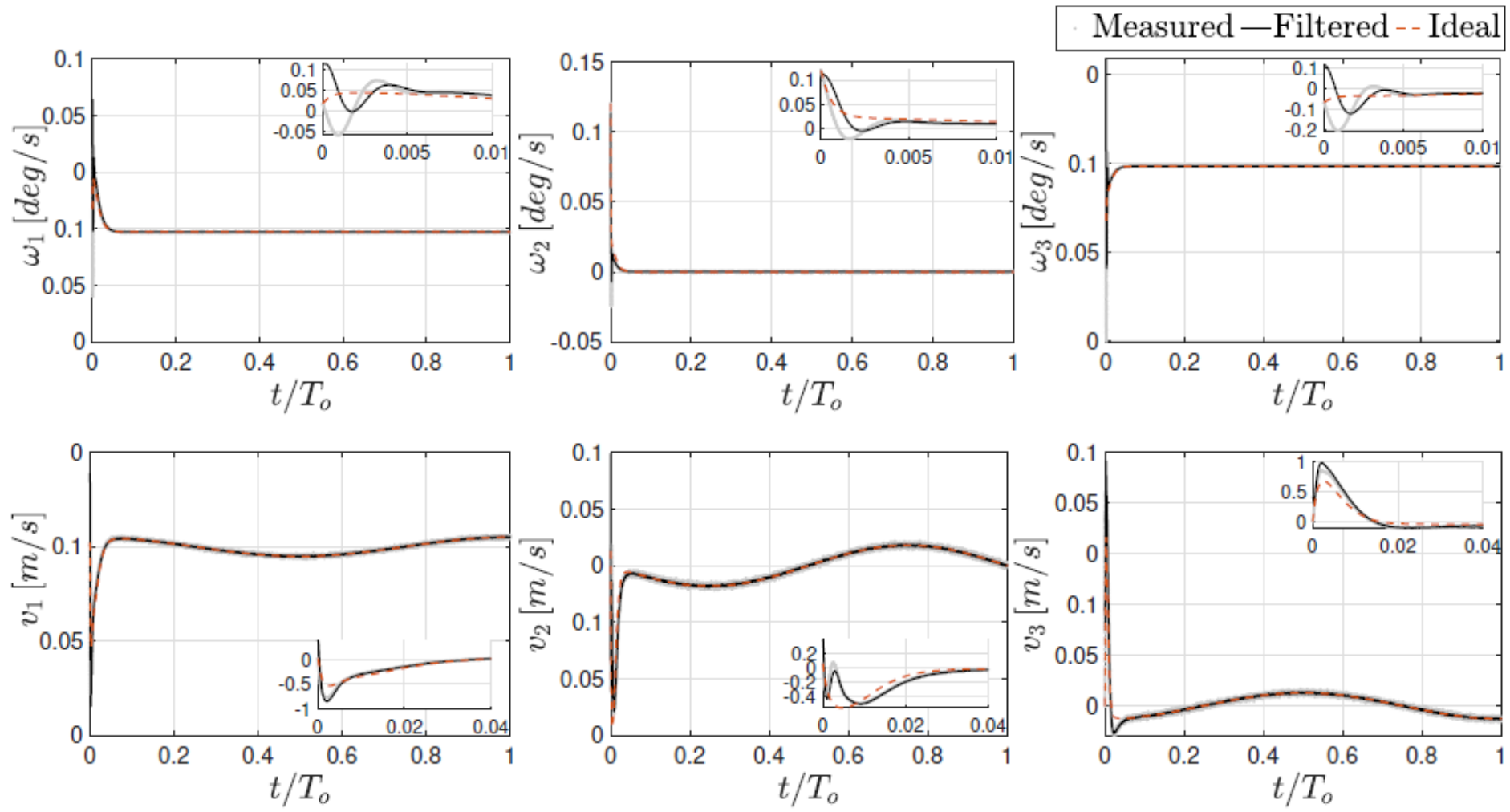

Figure 4 
Measured (grey), estimated (black), and ideal (red) states.

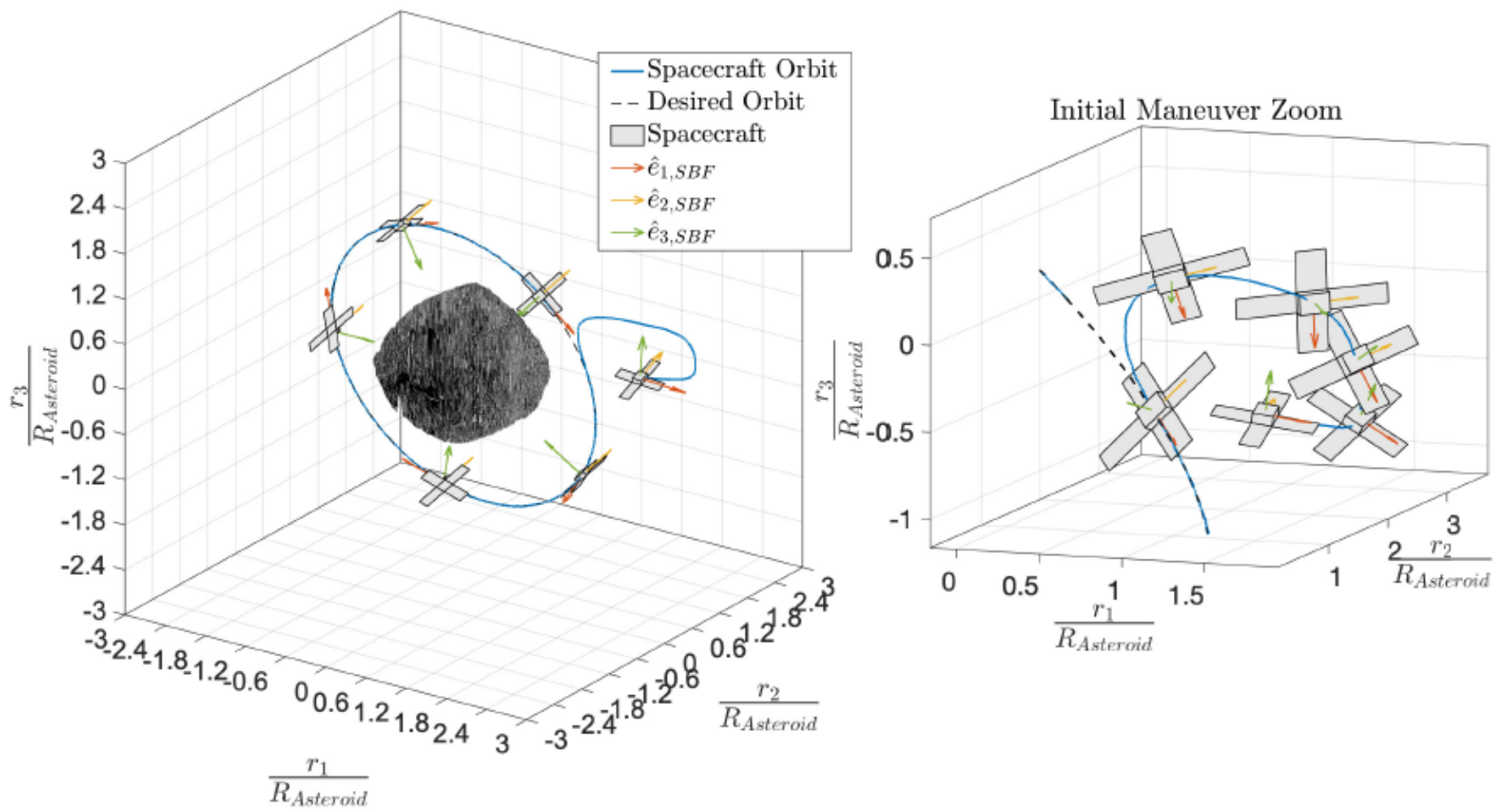

\section{Figure 5}

SBF orientation, and spacecraft attitude and trajectory around Bennu in $\mathrm{BCl}$ frame obtained via the implementation of the navigation and control systems. 

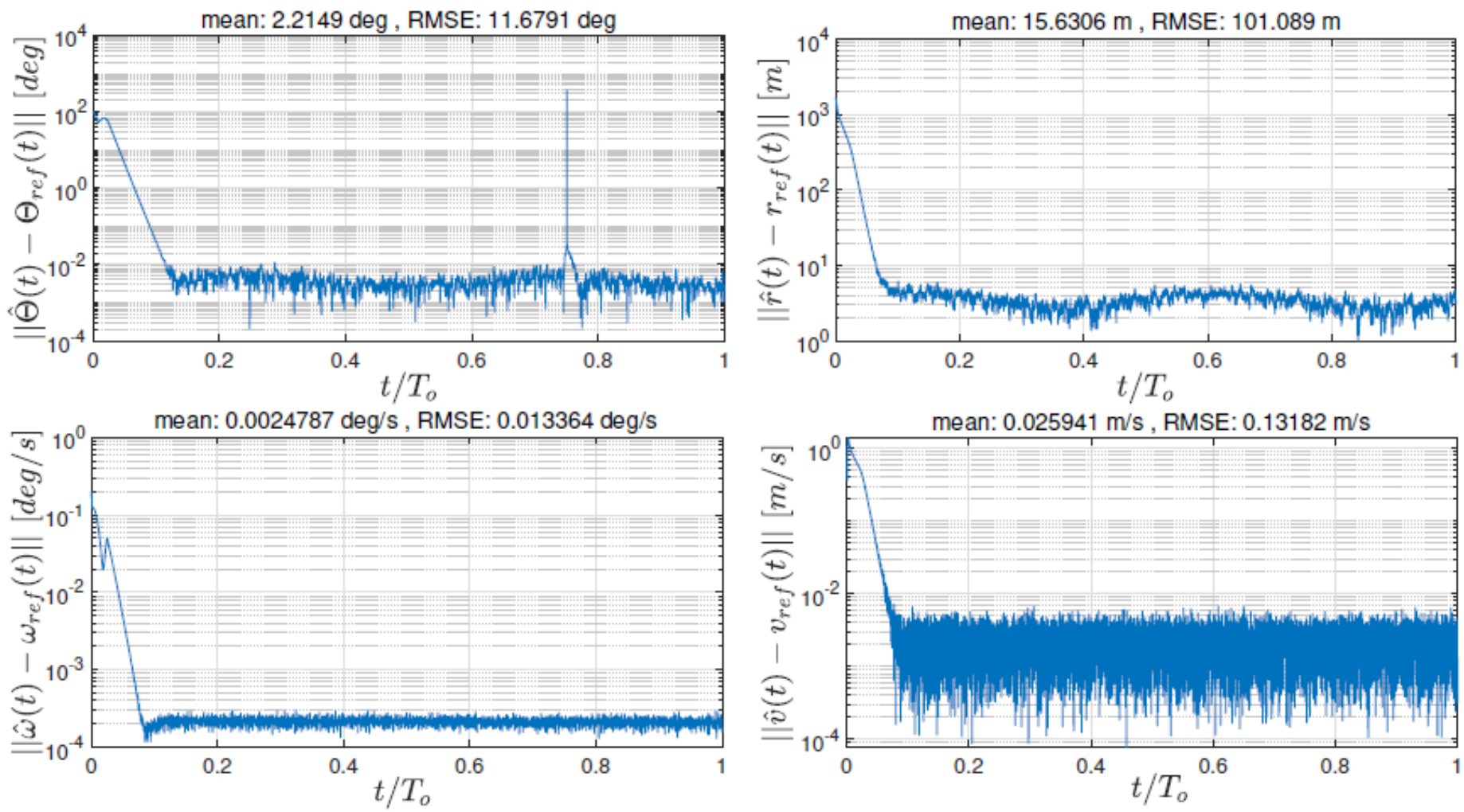

\section{Figure 6}

Norm of the difference between the estimated states and reference states 

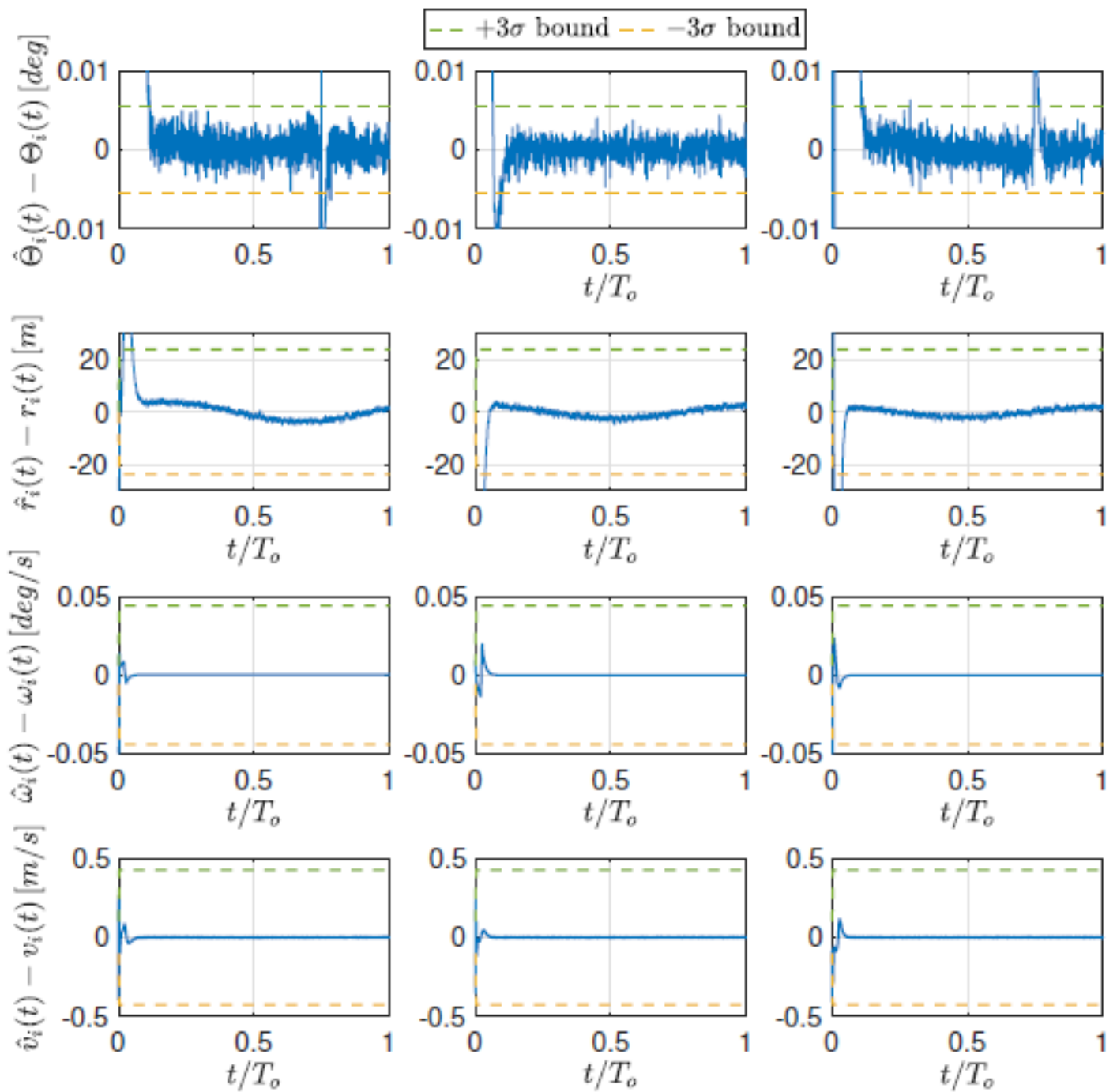

Figure 7

State estimation error components between the estimated states and the ideal noise-free states. 

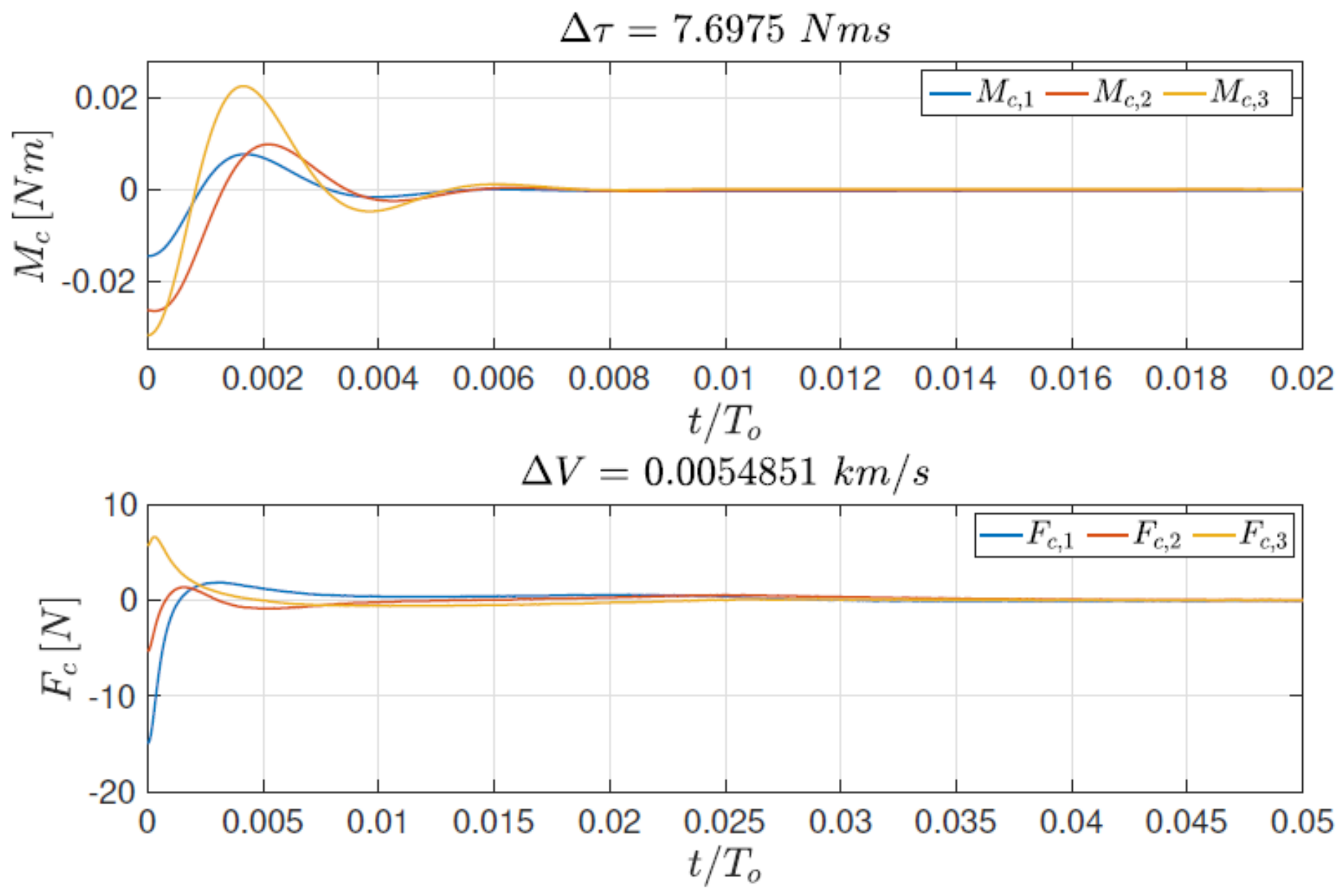

Figure 8

Control inputs in terms of force and moment provided by the tracking controller 